\title{
IV
}

\section{NOTAS SOBRE O PENSAMENTO EDUCACIONAL DE FLORESTAN FERNANDES*}

\author{
Janaina Lopes do Nascimento Duarte
}

\section{INTRODUÇÃO}

O ano de 2020 está marcado pela crise do capital agravada pela pandemia do Covid-19 no mundo e no Brasil, redefinindo dilemas e desafios e renovando as condições de dependência que se perpetuam na educação superior brasileira, marcada por um projeto não autônomo de ciência, tecnologia, produção e socialização do conhecimento. Nestes termos, as análises de Florestan Fernandes sobre a educação e a educação superior no capitalismo dependente, vinculando novas e antigas questões, podem fornecer relevantes chaves teóricas e políticas para compreensão e luta no presente.

Como resultado de revisão bibliográfica da obra florestaniana e estudos na linha de pesquisa "Educação e Serviço Social no capitalismo dependente", vinculada ao Grupo de Estudos Político-Sociais (POLITIZA/UnB), este texto tem como objetivo principal elucidar o pensamento educacional de Florestan, desvelando as relações entre padrão dependente de desenvolvimento e padrão dependente de educação, como ferramenta estratégica para a compreensão e o enfrentamento dos dilemas educacionais no Brasil.

Assim, este capítulo desenvolve-se a partir de dois eixos centrais: 1) o padrão dependente de educação como resultado de um padrão dependente de desenvolvimento e sua relação com o debate sobre heteronomia cultural; e 2) a condução da educação em um país capitalista dependente marcado pelas disputas de classe e no caráter antidemocrático da hegemonia burguesa. Por fim, tais eixos conduzem às considerações finais focadas na potência analítica do pensamento de Florestan Fernandes para decifrar os desafios educacionais do presente e contribuir com a rearticulação das lutas em defesa da educação pública.

*DOI- 10.29388/978-65-86678-36-9-0-f.77-94 


\section{PADRÃO DEPENDENTE DE DESENVOLVIMENTO E DE EDU- CAÇÃO ALIADO À LÓGICA DA HETERONOMIA CULTURAL}

Ao longo da sua vasta obra, Florestan Fernandes construiu uma problematização sobre a formação da sociedade brasileira que carrega grande relevância teórica e política: a concepção de capitalismo dependente como uma das formas que o desenvolvimento capitalista assume no decorrer de sua fase monopólica. As preocupações do autor se pautavam na especificidade latino-americana, em especial a brasileira, apresentando características próprias e singulares que transbordam para todas as esferas da vida, constituindo um padrão dependente de desenvolvimento capitalista. Cardoso (2005, p. 11, grifos nossos) analisa que " $[. .$.$] a importante descoberta que Florestan faz é a de que a particu-$ laridade Brasil pertence à generalidade capitalismo por meio da especificidade capitalista dependente".

Os países de capitalismo dependente assumem uma função determinada e integrada à lógica do capital que potencializa as relações entre desenvolvimento e subdesenvolvimento no capitalismo. Estas relações são determinadas pelos interesses e vínculos existentes nas conexões dialéticas da organização econômica, social, política e cultural entre as sociedades. Como afirma Fernandes (1995a, p. 139), “[...] não há como coincidir os tempos da história”, já que as sociedades consideradas dependentes e avançadas necessariamente apresentam tempos distintos em que processos de desenvolvimento capitalista se constituem de forma desigual, mas que também se combinam por associação.

$\mathrm{Na}$ verdade, as estruturas dos países capitalistas hegemônicos “[...] absorvem as estruturas dos países de capitalismo dependente, submetendo-as a seus próprios ritmos e subordinando-as aos interesses que lhes são próprios" (FERNANDES, 1995a, p. 139), no qual a periferia se conecta a partir da expropriação e exploração acentuada do trabalho, da manutenção de privilégios de uma minoria burguesa e da ampliação da desigualdade.

Por isso, para o autor, o capitalismo dependente se explica como

[...] uma situação específica, que só pode ser caracterizada através de uma economia de mercado capitalista duplamente polarizada, destituída de autosuficiência e possuidora, no máximo, de uma autonomia limitada. [...] uma entidade especializada, ao nível da integração do mercado capitalista mundial; uma entidade subsidiária e dependente, ao nível das aplicações reprodutivas do excedente econômico das sociedades desenvolvidas; e uma entidade tributária, ao nível do ciclo de apropriação capitalista internacional, no qual ela aparece como uma fonte de incrementação ou de 
multiplicação do excedente econômico das economias capitalistas hegemônicas (FERNANDES, 1972, p. 24, grifos nossos).

Fernandes (1972) analisa que um dos elementos estruturantes desse processo seria determinado pela condição colonial permanente do Brasil em relação aos países capitalistas hegemônicos, a partir da "[...] persistência de estruturas socioeconômicas herdadas do passado com a formação de estruturas socioeconômicas novas" (FERNANDES, 1975a, p. 62); ou seja, o "[...] capitalismo dependente gera, ao mesmo tempo, o subdesenvolvimento econômico, social, cultural e político, pois ele une o arcaico ao moderno e suscita seja a arcaização do moderno, seja a modernização do arcaico" (ibid., p. 61, grifos nossos), exigindo a fusão do moderno com o antigo na produção, no mercado e na organização das classes nas sociedades dependentes.

Essa condição se perpetua, mas também “[...] se redefine no curso da história, de tal modo que a posição heteronômica da economia do País, em sua estrutura e funcionamento, mantém-se constante" (FERNANDES, 1972, p. 14 nota 2 , grifos nossos), podendo variar a "[...] depender da calibração dos fatores externos envolvidos, da natureza do nexo de dependência, da polarização da hegemonia e do poder de determinação do núcleo dominante" (ibid., p. 15). Logo, a dinâmica da luta de classes se constitui como eixo estruturante deste processo, o que implica compreender " [...] como as classes se organizam e cooperam ou lutam entre si para preservar, fortalecer e aperfeiçoar, ou extinguir aquele regime social e econômico" (FERNANDES, 1972, p. 15), marcado pela relação de dependência com os centros hegemônicos.

Então, esse modelo exige determinado regime de classes, constituído por uma classe trabalhadora extremamente explorada e oprimida pela hegemonia de uma burguesia compósita, “[...] sempre pronta para incentivar decisões que dão prioridade ao crescimento econômico induzido, aceleram a modernização dependente e fazem abortar mesmo a 'revolução dentro da ordem"' (FERNANDES, 1975a, p. 57). Tal composição burguesa nos países dependentes se forja na dominação em sua dupla face, operando um padrão dual de expropriação do excedente econômico, no qual parte fica com a burguesia internacional e outra parte fica com a burguesia local brasileira ${ }^{2}$. Essa dinâmica alimenta a ma-

\footnotetext{
${ }^{1}$ Em Fernandes (1972), a noção de heteronomia (em contraposição à autonomia) está definida pela capacidade ou não de decisão, direção e gestão do processo de produção e de reprodução do capital nos países, determinando sua condição heterônoma (dependente) em relação ao desenvolvimento capitalista.

${ }^{2}$ A partir das obras de Fernandes, compreendemos que as chamadas burguesias locais não se definem ou se organizam a partir de marcos nacionais unificados e genéricos, mas se definem, so-
} 
nutenção simultânea, interna e externa, de renda, prestígio e poder, o que "[...] envolve, estrutural e dinamicamente, tanto uma extrema concentração interna da renda, quanto uma dominação externa e uma drenagem de recursos permanentes" (FERNANDES, 1975b, p. 28).

Fernandes (1975a, p. 45) esclarece que "[...] as aparências são de que estes setores (locais) sofrem a espoliação de fora para dentro". No entanto, as burguesias locais se constituem como parceiras ${ }^{3}$ (ainda que menores e subordinadas) das burguesias hegemônicas. Na verdade, a perda de riquezas “[...] se processa à custa dos setores assalariados e destituídos da população, submetidos a mecanismos permanentes de sobre apropriação e sobre expropriação capitalista" (FERNANDES, 1975a, p. 45).

A dominação burguesa ocorre a partir de processos combinados interna e externamente, como faces da mesma moeda que acarretam dilemas para as sociedades dependentes, a saber: a) estruturas econômicas, socioculturais, políticas que podem até absorver as transformações capitalistas, porém inibindo a integração nacional e o desenvolvimento autônomo; e b) dominação externa que estimula a modernização e o crescimento, mas impedindo a revolução nacional e uma autonomia de fato (FERNANDES, 1975a).

O regime de classes assume, como conexão histórico social do capitalismo dependente, uma dimensão peculiar: adaptar-se, em termos funcionais, a iniquidades econômicas insanáveis, a tensões políticas crônicas e a conflitos sociais insolúveis, elevando a opressão sistemática, reconhecida ou disfarçada, à categoria de estilo de vida (FERNANDES, 1972, p. 69, grifos nossos).

Assim, “[...] a dependência não é mera condição ou acidente [...] requer uma permanente vantagem estratégica do polo econômico hegemônico, aceita como compensadora, útil e criadora pelo polo dependente" (FERNANDES, 1975a, p. 54, grifo nosso). Nestes termos, o autor conclui:

bretudo, em função de interesses determinados pela sua própria natureza de classe (burguesa), em sintonia com a lógica do capital, cujos vínculos são profundos e diferenciados em relação às bur guesias internacionais. Por isso, preferimos o temo "burguesias locais".

${ }^{3}$ Fernandes (1995b, p. 134, grifos nossos) ressalta que "[...] a burguesia tende [...] a criar um espaço político seguro [...] essa burguesia só é débil para promover a revolução burguesa segundo o modelo 'clássico', nacionalista democrático. Ela é bastante forte para preservar o seu poder real, usar o Estado nacional para se proteger e, especialmente, para estabelecer políticas econômicas que assegurem continuidade e aceleração do crescimento econômico sem maiores repercussões no grau de democratização e de nacionalização das estruturas de poder". 
Na América Latina, o capitalismo e a sociedade de classes não são produtos de uma evolução interna [...] o capitalismo evoluiu na América Latina sem contar com condições de crescimento autossustentado e de desenvolvimento autônomo. Em consequência, classes e relações de classe carecem de dimensões estruturais e de dinamismos societários que são essenciais para a integração, a estabilidade e as transformações equilibradas da ordem social inerente à sociedade de classes. (FERNANDES, 1975a, p. 35, grifos do autor).

O capitalismo dependente gera condições objetivas de subdesenvolvimento pautado por uma "[...] beteronomia permanente" (FERNANDES, 1975a, p. 72, grifos nossos), sem possibilidades de sustentação de um modelo de desenvolvimento que seja de fato autônomo e que estimule a democracia ampliada e a garantia de direitos para a classe trabalhadora. Por isso, Fernandes (1975a, p. 59) analisa que a revolução burguesa na América Latina “[...] prendeu-se a condições estruturais e a ritmos históricos que fizeram dela o pivô da associação dependente e das sucessivas transições que rearticularam as economias nacionais às evoluções externas do capitalismo".

Tal padrão dependente de desenvolvimento acarreta repercussões importantes para o debate da educação, especialmente superior e pública, porque os elementos estruturantes do capitalismo dependente também mobilizam um padrão dependente educacional, já que as instituições educacionais são expressões da sociedade de classes em que se inserem. Como um dos eixos centrais da dependência é a falta de autonomia na condução dos processos, a educação também é constituída a partir de um processo de heteronomia cultural que só reproduz desigualdades (internas e, em relação aos países hegemônicos, externas)

As nações capitalistas dependentes participam das inovações e do conhecimento, contudo, estas inovações não desempenham os mesmos significados e funções sociais que desempenham nos países centrais, pois existem dois ritmos históricos superpostos, dois tempos históricos diferenciados, característicos do desenvolvimento desigual dos países e de sua inserção hierarquizada na divisão internacional e sociotécnica do trabalho. Enquanto os primeiros (países centrais) determinam os rumos da sua própria história, os países periféricos estão dependentes dos avanços tecnológicos e das políticas, adequando-se subordinadamente a suas mudanças. (LIMA, 2005, p. 328, grifos nossos).

Na formação sócio-histórica dependente brasileira é evidente a articulação das frações burguesas locais com as burguesias hegemônicas em prol dos 
interesses imediatos da periferia, "[...] dando suporte ao seu limitado horizonte intelectual (inclusive enquanto classe burguesa) e ao seu conservadorismo [...] assim, o crescimento da educação superior no Brasil não pode ser vinculado a um projeto nacional de desenvolvimento" (LIMA, 2005, p. 328). Florestan Fernandes explica:

As nações heteronômicas (ou dependentes) do mesmo mundo histórico cultural não têm alternativas. Permanecendo fiéis ao capitalismo, elas se condenam a um tipo de crescimento econômico e cultural, que pode ser descrito sob o conceito de 'desenvolvimento dependente' [...] (ocorrendo) em função de interesses e de dinamismos das sociedades hegemônicas, bem como das probabilidades de absorção de tais interesses e dinamismos por parte das sociedades heteronômicas. (FERNANDES, 1975b, p. 111, grifos nossos).

Assim, para o autor, imperialismo, capitalismo dependente, desenvolvimento/subdesenvolvimento, luta de classes e heteronomia cultural são categorias chaves para a compreensão histórica também do padrão dependente educacional no Brasil, especialmente quanto à educação superior. Isto porque

[...] a dependência socioeconômica e cultural traduz uma incapacidade relativa frustradora na livre produção e na livre utilização da riqueza. Enquanto as nações 'centrais' ou 'hegemônicas' absorvem parcelas consideráveis das riquezas (ou excedente econômico) produzidas nas nações subdesenvolvidas, estas como que se especializam, graças às funções espoliativas do capitalismo no mercado mundial, em exportar riquezas (o que envolve: perda sistemática de parcelas consideráveis do excedente econômico real ou potencial). Daí resultam muitas consequências, para a dinâmica da cultura e para o desenvolvimento educacional. (FERNANDES, 1975b, p. 141, grifos nossos).

Por isso, no Brasil, a natureza da burguesia brasileira, sua constituição e hegemonia no curso da história (em associação com a burguesia imperialista) não deixam dúvida de que este é um aspecto estruturante para entender o padrão dependente no Brasil. Então, para uma "sociedade que não viveu a revolução burguesa clássica ${ }^{4}$, a concepção burguesa de revolução educacional significa um conjunto de avanços relativos que podem ameaçar a concentração de renda,

\footnotetext{
${ }^{4}$ Assim como na América Latina, Fernandes (1995a, p. 142) analisa que a Revolução Burguesa no Brasil tem “[...] sua evolução em quadros particulares, que não levam à revolução burguesa clássica, nem ao Estado representativo democrático burguês ou à autonomia nacional. É preciso romper com o modelo clássico para compreender o capitalismo da periferia e aonde ele conduz".
} 
prestígio social e poder que a consolida historicamente enquanto classe" (LIMA, 2019, p. 13).

No âmbito da educação superior, "[...] as universidades das nações subdesenvolvidas também estão inseridas nessas relações de dependência e concorrem para preservar as formas de subordinação cultural existentes [...]" (FERNANDES, 2010, p. 267), ficando à mercê das relações dinâmicas entre uma burguesia local agressiva, com traços elitistas, e uma classe trabalhadora historicamente oprimida com pouco acesso ao poder decisório (FERNANDES, 1995a). É o que constitui, na sociedade brasileira, uma educação superior sempre marcada pelas relações de opressão, desigualdade aguçada e dominação autocrática burguesa, cuja função central é atender às necessidades da relação de dependência com o imperialismo.

Para materializar tal processo, destaca-se a atuação histórica dos organismos internacionais, já desde o período da ditatura civil militar, como analisou Florestan (FERNANDES, 1975b), tais como a ação da Aliança para o Progresso, os acordos MEC/USAID, da OEA, do Banco Mundial, do Banco Interamericano de Desenvolvimento, sob a condução norte-americana, concretizando as condições de um padrão de educação superior adequado às exigências do capitalismo monopolista, sob intensa condução interna das frações da burguesia brasileira.

A dependência econômica, política e a heteronomia cultural mantêm a universidade tutelada a partir de fora (imperialismo) e de dentro (burguesia brasileira e seus interesses), definindo como função da educação superior a transplantação de conhecimentos e a adaptação de 'mentes e corações' à ordem burguesa. (LIMA, 2005, p. 329, grifos nossos).

Situação que permanece sem alterações substantivas na natureza desta relação de dependência educacional à brasileira, manifestando-se especialmente por meio: a) da ampliação da privatização da educação superior, com expansão das instituições privadas e com a privatização interna das universidades públicas, em especial com as parcerias público e privado; b) o processo de desmonte do setor público, sem investimentos há décadas, com o comprometimento da sua autonomia, etc. (DUARTE, 2017); e c) "[...] no esforço de ajustar a produção intelectual da universidade pública, especialmente da pesquisa científica e tecnológica, aos interesses privados nacionais e internacionais" (LIMA, 2005, p. 330-331).

Como afirma Florestan, “[...] jamais poderia engendrar, por si mesma, o tipo de universidade suscetível de romper com a situação de dependência e de 
superar o subdesenvolvimento" (FERNANDES, 1975b, p. 114), pois sua superação, de fato, vincula-se à luta pela democratização da universidade e da sociedade.

\section{CONDUÇÃO DA EDUCAÇÃO EM UM PAÍ́S CAPITALISTA DEPEN- DENTE}

Para tratar sobre a educação e seu padrão dependente, a partir de Florestan Fernandes, é preciso considerar que "[...] a análise do seu pensamento educacional só pode ser realizada quando inserida em sua produção sociológica e em sua militância política" (LIMA, 2005, p. 307). Assim, Florestan apresenta em suas obras o vínculo dialético entre o rigor científico e a relevância social de seus estudos, pois, para ele, “[...] só existe relevância científica, quando existe relevância social que aponte para a transformação das relações sociais, e não para sua conservação" (LIMA, 2005, p. 307, grifos nossos), indicando o compromisso político e social do pesquisador/cientista com seu objeto de estudo: "[...] qualquer cientista social que se ajuste ao objeto de pesquisa, sem levar em conta o que a própria pesquisa representa no contexto histórico social investigado, arrisca-se a produzir conhecimentos 'superficiais' e 'irrelevantes"' (FERNANDES, 1972, p. 17). Na explicação prévia de outra obra importante, o autor também explica:

[...] partamos do concreto ao abstrato ou façamos o caminho inverso, estamos sempre no centro dos dramas coletivos e procuramos entender os rumos sociológicos da história. [...] Os ensaios aqui reunidos exprimem em cheio essa situação e dela extraem sua força, como testemunho de interpretação militante. (FERNANDES, 1975a, p. 9, grifos nossos).

Lima (2005, p. 310), analisando a obra de Florestan, destaca que o padrão dependente de educação superior “[...] está alicerçado no padrão de integração societária da economia mundial, isto é, está articulado com a posição que o Brasil ocupa na divisão internacional do trabalho e relacionado com a configuração da luta de classes" na formação histórica e social brasileira. O debate sobre heteronomia, à luz do desenvolvimento necessariamente desigual entre periferia e centro no capitalismo, espraia-se para o debate educacional, no qual o centro do " $[. .$.$] problema estaria no capitalismo dependente que não exclui a$ questão cultural, mas a redefine no escopo das tensões entre desenvolvimento autônomo e capitalismo dependente" (LEHER, 2012, p. 1163). 
De acordo com Lima (2005, p. 309), “[...] os eixos centrais da obra de Florestan sobre o debate educacional", em vários momentos da sua obra, podem ser sintetizados pela defesa: a) de um sistema nacional de educação laica, financiado e direcionado pelo Estado; b) da destinação de verbas públicas para financiar exclusivamente a educação pública; c) do acesso democratizado de todos os níveis da educação; e d) do papel da educação no processo de ruptura com o capitalismo dependente (LIMA, 2005).

\subsection{Campanha em Defesa da Escola Pública}

A participação engajada de Florestan na "Campanha em Defesa da Escola Pública" ${ }^{5}$ destaca-se no contexto das discussões para a aprovação da Lei de Diretrizes e Bases, expondo "[...] em relevo o embate político que convulsionou o final do processo de tramitação da Lei n. 4.024/1961 e, também, sua caracterização dos desafios educacionais" (LEHER, 2012, p. 1163).

Florestan defendia que a "[...] democratização do ensino pode ser apreciada tanto como requisito da ordem social democrática, quanto como fator de seu aperfeiçoamento" (FERNANDES, 1966, p. 124), já que “[...] não existe democracia sem democratização do ensino" (ibid., p. 124, grifos nossos). Portanto, é necessária a universalização das oportunidades educacionais: “[...] um país tende a democratizar seu sistema de ensino quando procura atenuar ou abolir as barreiras extraeducacionais que restrinjam ao uso do direito à educação e o convertam, aberta ou disfarçadamente, em privilégio social” (ibid., p. 123). No entanto, as disputas burguesas caminharam em outra direção:

[...] ocorreu um acirramento do debate em torno da aprovação da lei com a apresentação de um substitutivo, por Carlos Lacerda, elaborado por um grupo de educadores e intelectuais leigos e católicos ligados aos empresários do ensino privado e às escolas confessionais. [...] passando a reivindicar, no substitutivo, igualdade de condições da escola privada em relação à escola pública. Por trás do argumento da liberdade de ensino, estavam interesses puramente comerciais e, por parte do grupo católico, havia ainda os interesses de ordem doutrinária que objetivava recuperar a influência que a Igreja exercera no sistema educacional. (SILVA, 2005, p. 83).

\footnotetext{
${ }^{5}$ Campanha de grande mobilização e participação de profissionais, intelectuais, estudantes e líderes sindicais, organizada em defesa da escola pública nos anos 1960 e que, neste contexto, contou com a publicação de diversos textos de Florestan, atraindo diferentes setores da sociedade para o debate e a luta pela escola pública, pela destinação de recursos públicos exclusivos para escolas públicas e pela democratização do ensino.
} 
Florestan Fernandes conclui, e aprofunda posteriormente, que "[...] nem mesmo reformas liberais são abraçadas pelos setores dominantes que, mais do que descaso, passam a se engajar, de modo organizado e orgânico, contra a modesta reforma educacional" (LEHER, 2012, p. 1164) contida na LDB de 1961.

Cometeu-se um crime contra o ensino, atendendo-se às pretensões das correntes privatistas e às pressões reacionárias de círculos católicos e obscurantistas. [...] Acomoda-se (o congresso) quando devia revoltar-se: omite-se ou tergiversa, quando devia decidir e impor soberanamente as soluções mais convenientes à democratização do ensino e à diferenciação quantitativa ou qualitativa do sistema educacional brasileiro. (FERNANDES, 1966, p. 514, grifos nossos).

Portanto, Florestan avalia que a LDB de 1961 caracteriza o afastamento das " [...] necessidades de educação e das aspirações de desenvolvimento econômico, político, social e cultural" (FERNANDES, 1966, p. 528) do nosso

país, "[...] sendo manipulada de forma conservantista e segundo interesses sociais egoísticos das camadas dominantes" (ibid., p. 529), não reunindo "[...] condições para operar estrutural e dinamicamente como fator social construtivo nas relações do sistema educacional com o meio social circundante" (ibid., p. 529).

Entre o final dos anos 1960 e meados dos anos 1970, Florestan redefine suas preocupações teórico políticas, especialmente a partir do debate sobre capitalismo dependente e do seu regime de classes, refinando suas interpretações sobre os dilemas e desafios educacionais, em particular a partir dos anos 1980.

\subsection{Período da Constituinte, Constituição de 1988, lutas pela nova LDB e traços de continuidade com o projeto neoliberal: faces dis- tintas da mesma disputa}

A partir dos seus estudos sobre capitalismo dependente e heteronomia cultural, nos anos 1980 e 1990, Florestan se dedicou ao aprofundamento da questão educacional no Brasil, sendo um dos seus principais trabalhos "O desafio educacional” (FERNANDES, 1989). No prefácio desta obra, o autor já enuncia uma síntese do seu pensamento educacional nos anos 1980: “[...] este livro reúne artigos que apanham aspectos da erupção de um vulcão que parecia extinto. [...] clamam por uma revolução educacional' (FERNANDES, 1989, p. 910, grifos nossos). Nesta direção "intelectual militante", Florestan expõe dois 
aspectos importantes sobre a educação e suas relações dinâmicas com a sociedade:

$\left.1^{\circ}\right)$ A transformação da Educação depende de uma transformação global e profunda da sociedade; e $2^{\circ}$ ) a própria educação funciona como um dos fatores de democratização da sociedade e o sentido de qualquer 'política educacional democrática’ tem em vista determinadas transformações essenciais da sociedade. Diríamos que educação e democratiz̧ação da sociedade são entidades reais e processos concretos interdependentes. (FERNANDES, 1989, p. 13, grifos do autor).

Embalado pelos movimentos sociais e sindicais que se reorganizam no contexto da redemocratização, pressionando a abertura política, pelas tensões com a burguesia para manutenção, em novos termos, da sua hegemonia pós ditadura, Florestan mergulha nas lutas pela democracia e em defesa da educação, mas de modo renovado quando comparado à Campanha dos anos 1960, pois a conjuntura era outra e trazia novas exigências. Cabe lembrar que a herança da ditadura civil militar acarretou alterações importantes na educação a partir de "reformas consentidas", tais como a Reforma do Ensino Primário e Secundário de 1971 e a Reforma Universitária de 1968, desmobilizando os movimentos sociais na área de educação, padronizando a formação e o trabalho nas universidades, priorizando o setor privado e permitindo a transferência de recursos públicos para aquele setor (DUARTE, 2017). Por isso, Florestan acreditava na via de uma revolução educacional, desencadeada pela classe trabalhadora, pois

[...] não há que deixar margem para enganos e ilusões. Retomar, hoje, a revolução nacional e a revolução democrática, combater, hoje, a descolonização prolongada, o desenvolvimento desigual, a dependência e o imperialismo significam ver claramente que o sistema educacional deve ser pensado e ativado quantitativa e qualitativamente. (FERNANDES, 1989, p. 18, grifos nossos).

Esta direção alimenta as ações de Florestan como deputado federal pelo PT entre 1986 e 1993, especialmente em dois momentos fundamentais para a educação brasileira: a elaboração da Constituição de 1988 e a construção da LDB de 1996. Na sua perspectiva, quanto à educação, deveriam ser três os conjuntos de prioridades constitucionais: 1) a garantia a todos de igualdade efetiva das oportunidades educacionais como "norma imperativa e autoaplicável", suprimindo as desigualdades de classes; 2) a orientação firme na formalização de valores não incorporados do exterior, no qual a escola é o principal "labora- 
tório" de uma sociedade civil civilizadora, pluralista e democrática, envolvendo a valorização de trabalhadores da educação (professores e outros), a fim de lutar para reverter a situação de "degradação deliberada"; e 3) a autoemancipação pedagógica em escala nacional, que promovesse o desenvolvimento autônomo, em oposição aos "pacotes educacionais" historicamente incorporados na experiência brasileira (FERNANDES, 1989, p. 133-135).

Segundo Leher (2012), Florestan apresentou 94 emendas, destas 46 relacionadas à educação, das quais: 27 foram de natureza conceitual ou sobre a organização da educação brasileira, 07 de questões sobre Ciência e Tecnologia $(C \& T)$ e 03 sobre a universidade. Entre suas emendas mais relevantes, Leher (2012, p. 1167) destaca:

a) direito dos povos indígenas à educação bilíngue; b) autonomia universitária (art. 207); c) diversos dispositivos de apoio às atividades de C\&T; d) gratuidade da educação para crianças de 0 a 6 anos em instituições especializadas; e) obrigatoriedade da educação pública e gratuita dos 6 aos 16 anos; f) proibição de ensino religioso nas escolas públicas; g) verbas públicas exclusivamente para as escolas públicas; h) financiamento: a União aplicará anualmente não menos de $18 \%$, e os estados, o Distrito Federal e os municípios não menos de $25 \%$ das suas receitas totais (e não apenas a resultante de impostos) na manutenção e desenvolvimento das atividades de ensino; i) dispositivo que preveja, em dez anos, que nenhuma instituição privada receberia verbas públicas; e, j) enfrentando a questão do caráter público da educação estatal, criação do Conselho Nacional de Desenvolvimento da Educação, o qual deverá possuir autonomia administrativa e financeira frente ao MEC, bem como autoridade para estabelecer programas e políticas a serem realizados através do Plano Nacional de Educação.

Algumas propostas foram incorporadas total ou parcialmente e outras foram suprimidas do texto final, em razão das disputas políticas presentes naquele contexto, revelando, segundo Fernandes (1989, p. 133), que “[...] só é 'constitucional' o que não se choca com as prioridades educacionais e os interesses econômicos ou ideológicos dos donos do poder”. Para o autor, na verdade, "[...] ficou faltando a coragem de converter o projeto de texto em passo decisivo na direção de uma reforma educacional irreversivel e radical' (FERNANDES, 1989, p. 133, grifos nossos).

Ainda que tenha apresentado avanços, em matéria de educação, a Constituição de 1988 impôs também retrocessos, tais como: a) art. 208, item V, expõe o acesso à educação superior "segundo a capacidade de cada um", portanto, não assegurando seu acesso como direito de todos; b) art. 209, assegura 
que "o ensino é livre à iniciativa privada"; c) art. 210, possibilita o ensino religioso nas escolas públicas; e d) art. 213, permite a admissão de verbas públicas para as instituições privadas (DUARTE, 2017).

As preocupações de Florestan se estenderam para o contexto das disputas presentes na construção da Lei de Diretrizes e Bases da Educação Nacional nos anos 1990, pois compreendia que "[...] a LDB, para ter sentido, precisa desfocar-se do tope, ela precisa focar-se na base da sociedade" (FERNANDES, 1989, p. 239, grifos nossos), chamando à participação os movimentos sociais e toda a sociedade:

Hoje, a prioridade cabe à $L D B$. É preciso calibrá-la para o presente, tanto quanto para o futuro próximo e remoto. Essa é uma forma de 'pressão externa’ que precisa ser desencadeada com extrema intensidade sobre o Parlamento. Contudo, para além dessa prioridade prevalece o significado da educação para promover a descolonização, a revolução nacional, a revolução democrática que a República autocrática burguesa bloqueou e mistificou. (FERNANDES, 1989, p. 10, grifos nossos).

Sobre os embates na elaboração da nova LDB, Florestan destacou em escritos para a Folha de São Paulo: "Inquietos, os setores privatistas montam, de novo, um funesto campo de batalha para manter suas vantagens relativas. É nosso dever enfrentá-los, sem desalento, para derrotar sua hegemonia e mercantilismo" (FERNANDES, 1995b, p. 26). E, novamente, a correlação de forças não foi favorável aos movimentos em defesa da educação pública e democrática.

Florestan apoiava o projeto de LDB aprovado na Câmara dos Deputados e trabalhado pelo relator do Senado Federal - Cid Sabóia -, uma vez que considerava aquele projeto de lei renovador e representativo de amplos setores da sociedade. Entretanto, o que ocorreu foi a aprovação, no Senado Federal, do projeto de LDB do senador Darcy Ribeiro. Esse projeto negou, mais uma vez, a esperança de elaboração de leis que possibilitassem a constituição de um sistema de ensino público e democrático. (HECKERT, 2005, p. 116).

Neste sentido, as chaves teóricas fornecidas nas obras de Florestan Fernandes permitem compreender que os setores da burguesia local, em associação permanente com a burguesia hegemônica, "[...] não poderiam ser protagonistas de reformas sociais universalistas sequer nos marcos da 'revolução dentro da ordem', como os desfechos da LDB de 1961 e 1996 atestaram” (LEHER, 2012, p. 1169-1170). Cabe lembrar, a partir de Florestan, que as burguesias na Améri- 
ca Latina foram "[...] os artífices do capitalismo dependente. Escolheram-no e o fortaleceram como alternativa a uma revolução nacional dentro da ordem" (FERNANDES, 1975a, p. 59).

$\mathrm{Na}$ verdade, a LDB de 1996 “[...] contribuiu para alicerçar as bases para as reformas educacionais que viriam a ser implantadas no Brasil ao final dos anos 1990, privatizando cada vez mais a educação brasileira" (HECKERT, 2005, p. 117). Após os anos 1990 e já entrando nos anos 2000 ocorreram profundas alterações na correlação de forças, incluindo aqui as forças sociais já analisadas por Florestan e as novas articulações sob o amparo do projeto neoliberal, promovendo arranjos e rearranjos na hegemonia burguesa local em associação com a hegemônica, em prol dos seus interesses privatistas também na educação; não alterando o padrão dependente educacional no Brasil. Como sintetiza Leher (2012, p. 1170), “[...] está em curso uma internacionalização de novo tipo no setor, por meio de fundos de investimentos multinacionais, em geral com ações nas bolsas de valores, que vêm promovendo vertiginosa concentração da educação superior privada".

Neste contexto, a universidade brasileira enfrenta uma grave crise a partir dos anos 1990 "[...] imposta pela crise constante do capital em sua busca incessante pela lucratividade” (LIMA, 2019, p. 15). Assim, a expansão da educação superior é marcada por uma ampliação do acesso que "[...] ocorre, historicamente, associada à ação direta do setor privado na área educacional, caracterizando um eixo estruturante da educaşão superior no capitalismo dependente" (LIMA, 2019, p. 15, grifos nossos).

Então, o padrão dependente brasileiro imposto historicamente em todos os níveis da educação, expressa o papel da educação superior na periferia capitalista, como

[...] um importante campo de exploração lucrativa para os setores privados brasileiros e internacionais, a transmissão e adaptação de conhecimentos produzidos nos países centrais para formação aligeirada dos trabalhadores e a formação de quadros dirigentes, quando direcionada aos filhos da burguesia. A partir deste quadro analítico, o dilema educacional brasileiro, para Florestan Fernandes, articula os padrões dependentes de desenvolvimento e de educação superior. (LIMA, 2019, p. 14).

De fato, desde o período civil militar, aprofundando-se nas décadas de 1990 e 2000, os ciclos expansivos da educação superior se constituem a partir de duas características estruturantes que se revitalizam ao sabor da dinâmica entre as classes fundamentais e suas frações, especialmente burguesas em associa- 
ção interna e externa: a) o privilegiamento do setor privado; e b) o desmonte (por dentro) do setor público. O que está em evidência é sempre um conjunto de reformas que, no capitalismo dependente, caracterizam-se como "[...] manipulações sutis ou descaradas de preservação do status quo e de revitalização do poder conservador" (FERNANDES, 1975b, p. 11, grifo do autor).

Logo, a luta pela democratização da educação pública, básica e, especialmente, superior no capitalismo dependente, já defendida por Florestan desde anos 1950/1960, continua sendo urgente e necessária, pois "[...] o atraso educacional acompanha o subdesenvolvimento econômico e a dependência cultural [...] e o conservantismo tosco ou egoístico, assim, possui um conteúdo neocolonial certo: o incentivo à alienação das consciências" (FERNANDES, 1995b, p. 6, grifos nossos). Por conseguinte, a agenda permanece a mesma: a luta responsável e corajosa pela educação pública, "[...] o repúdio a uma herança sórdida e a supressão da mesma mediante a autonomia da razão pedagógica" (ibid., p. 6).

\section{CONSIDERAÇÕES FINAIS}

O capitalismo dependente em solo brasileiro, a partir de Florestan Fernandes, realiza a renovação dos padrões dependentes de desenvolvimento e de educação, ratificando desigualdades, concentração de renda, de prestígio social e de poder. O diálogo com Fernandes pode contribuir com férteis reflexões e críticas e promover melhores condições para o enfrentamento do projeto neoliberal privatista e desumano em curso, que defende interesses da hegemonia compósita burguesa no Brasil. É preciso lembrar que "[...] as ações políticas da burguesia brasileira demonstram que seu horizonte político ultraconservador e elitista inviabiliza qualquer ruptura com o padrão dependente de educação superior" (LIMA, 2005, p. 326).

Nas palavras de Florestan Fernandes (1995b, p. 14), “[...] apresenta-se como uma proclamação viva, a necessidade de que nos unamos para enfrentar e resolver o desafio educacional. Exige a ruptura total com a tradição elitista de ignorância para o povo". Assim, precisamos repensar e realimentar nossa capacidade de luta e a priorização dos dilemas brasileiros, pondo a ciência a seu serviço, e colocando no centro da agenda a educação pública. Pois, é “[...] necessário despertar, em amplos setores, a consciência de seus interesses educacionais, de modo a incluir, em seu horizonte intelectual, uma nova concepşão de sua condição humana, de sua situação social e do seu futuro" (FERNANDES, 1975b, p. 137, grifos nossos). 
Em tempos áridos como o presente, precisamos reafirmar o compromisso com a educação pública, no sentido de poder garantir direitos, disputar o projeto de educação como direito e estimular, nos estudantes, docentes, trabalhadores em geral, a capacidade de reinvenção da luta por uma educação de fato emancipatória que extrapole seus muros e currículos, porque, como afirma Bertolt Brecht: "Nada é impossivel de mudar". A educação, especialmente a educação superior, pode ser uma importante chave para o enfrentamento do capitalismo dependente e suas inerentes formas de superexpropriação e superexploração.

\section{REFERÊNCIAS}

CARDOSO, M. L. Sobre a teorização do capitalismo dependente em Florestan Fernandes. In: FÁVERO, O. (org.). Democracia e educação em Florestan Fernandes. Campinas: Editora Autores Associados; Niterói: Editora da Universidade Federal Fluminense. EDUFF, 2005. p. 07-40.

\section{DUARTE, J. L. do N. Trabalho Docente do Assistente Social nas Fede-} rais: contradições e resistências em tempos de intensificação e produtivismo acadêmico. 2017. 467 f. Tese (Doutorado em Serviço Social) - Escola de Serviço Social, Universidade Federal do Rio de Janeiro, Rio de Janeiro, 2017.

FERNANDES, F. Educação e Sociedade no Brasil. São Paulo: EDUSP/ Dominus, 1966.

Sociedade de classes e subdesenvolvimento. Biblioteca de Ciências Sociais. Rio de Janeiro: Zahar, 1972.

. Capitalismo dependente e classes sociais na América Latina. 2. ed. Rio de Janeiro: Zahar, 1975a.

FERNANDES, F. Universidade brasileira: reforma ou revolução? São Paulo: Alfa-Omega, 1975b.

O desafio educacional. São Paulo: Cortez e Autores Associados, 1989.

\footnotetext{
${ }^{6}$ Poema, com mesmo título, de Eugen Berthold Friedrich Brecht (1898-1956), destacado dramaturgo, poeta e encenador alemão do século XX. Disponível em: < https://www.escritas.org/pt/ t/13207/nada-e-impossivel-de-mudar $>$ Acesso em: 31 jul. 2020.
} 
. Capitalismo Dependente e Imperialismo. In: FERNANDES, Florestan. Em busca do socialismo: últimos escritos e outros textos. São Paulo: Xamã, 1995a. p. 139-144.

. Tensões na educação. Salvador: Sarah Letras, 1995b.

. A universidade em uma sociedade em desenvolvimento. In: FERNANDES, Florestan. Circuito Fechado - quatro ensaios sobre o "poder institucional". São Paulo: Globo, 2010. p. 201-298.

HECKERT, A. L. C. Florestan Fernandes e a década de 1980. In: FÁVERO, O. (org.). Democracia e educação em Florestan Fernandes. Campinas: Editora Autores Associados. Niterói: Editora da Universidade Federal Fluminense. EDUFF, 2005. p. 109-118.

LEHER, R. Florestan Fernandes e a defesa da educação pública. Revista Educação e Sociedade - Ciências da Educação, Campinas, v. 33, n. 121, p. 1157 1173, out./dez. 2012.

LIMA, K. Reforma da Educação Superior nos anos de contrarrevolução neoliberal: de Fernando Henrique Cardoso à Luís Inácio Lula da Silva. 2005. 483 f. Tese (Doutorado em Serviço Social) - Faculdade de Educação, Universidade Federal Fluminense, Niterói, 2005.

. Desafio educacional brasileiro e ofensiva ultraconservadora do capital. Universidade e Sociedade, Edição Especial América Latina - outubro de 2019. Brasília, ano XXIX, p. 8-39, out. 2019.

SILVA, A. F. Florestan Fernandes e a educação brasileira nas décadas de 1950 e 1960. In: FÁVERO, O. (org.). Democracia e educação em Florestan Fernandes. Campinas: Editora Autores Associados; Niterói: Editora da Universidade Federal Fluminense. EDUFF, 2005. p. 79-86. 